Check for updates

Cite this: RSC Adv., 2017, 7, 35357

\title{
Hierarchically organized Li-Al-LDH nano-flakes: a low-temperature approach to seal porous anodic oxide on aluminum alloys $\uparrow$
}

\author{
D. Mata, (D) *a M. Serdechnova, ${ }^{\text {b }}$ M. Mohedano, ${ }^{\text {bc }}$ C. L. Mendis, ${ }^{\text {bd }}$ S. V. Lamaka, ${ }^{\text {b }}$ \\ J. Tedim, ${ }^{\text {e }}$ T. Hack, ${ }^{f}$ S. Nixon ${ }^{f}$ and M. L. Zheludkevich ${ }^{\text {bg }}$
}

\begin{abstract}
This work suggests a low-temperature sealing approach for tartaric-sulfuric acid (TSA) anodized AA2024 based on hierarchically organized Li-Al-layered double hydroxide (LDH) structures. The new proposed sealing is expected to be directly competitive to the standard hot water sealing (HWS) approaches because of its reduced treatment temperature and high protection efficiency. A hierarchical organization of in situ formed LDH nano-flakes across the depth length of the TSA pores, from the macrodown to the nano-size range, was observed with transmission electron microscopy (TEM). Electrochemical impedance spectroscopy (EIS) studies showed that the densely packed LDH arrangement at the porous oxide layer is directly related to the drastically improved barrier properties of TSA. Moreover, LDH flakelike structures worked as "smart" reservoirs for corrosion inhibiting vanadium species $\left(\mathrm{VO}_{x}\right)$ that are released on demand upon the onset of corrosion. This was confirmed using a scanning vibrating electrode technique (SVET), giving relevant insights into the time-resolved release activity of $\mathrm{VO}_{x}$ and the formation of the passivation layer on cathodic intermetallics, corroborated with EDX and analytical Raman spectroscopy. Passive and active corrosion protection was imparted to the anodic layer via new $\mathrm{Li}-\mathrm{Al}-\mathrm{LDH}$ structures with long-term protection exceeding that of standard HWS procedures.
\end{abstract}

Received 17th May 2017

Accepted 6th July 2017

DOI: 10.1039/c7ra05593e

rsc.li/rsc-advances

\section{Introduction}

The escalating fabrication demands for "green" aircrafts following the latest European guidelines have set new challenges in the selection of materials and processes in the aeronautic industry. The eco-design of pioneering surface treatments against corrosion failure with performance and costs matching those of the chromate-based ones is a challenge up to date. ${ }^{1}$

Relevant breakthroughs in new protective systems free of toxic chromates have been done in recent years, particularly for $2 \mathrm{xxx}$ series aluminum alloys such as AA2024, which has been widely

${ }^{a}$ Smallmatek - Small Materials and Technologies, Rua dos Canhas, 3810-075 Aveiro, Portugal.E-mail: diogo.mata@smallmatek.pt

${ }^{b}$ Institute of Materials Research, Helmholtz-Zentrum Geesthacht, Max-Planck-Straße 1, 21502 Geesthacht, Germany

'Departamento de Ciência de Materiales, Facultad de Ciências Quimicas, Universidad Complutense, 28040 Madrid, Spain

${ }^{d}$ Brunel - Centre for Advanced Solidification Technology, Brunel University London, Uxbridge UB8 $3 P H, U K$

${ }^{e}$ CICECO, Dep. Materials and Ceramic Engineering, University of Aveiro, 3810-193, Aveiro, Portugal

${ }^{f}$ Airbus Group Innovations, 81663 Munich, Germany

${ }^{8}$ Faculty of Engineering, Christian-Albrechts-University of Kiel, Kaiserstr. 2, D-24143 Kiel, Germany

$\dagger$ Electronic supplementary information (ESI) available. See DOI: 10.1039/c7ra05593e explored in the aeronautic industry. An important step-forward in this crossroad was accomplished through successful replacement of chromic acid anodizing (CAA) by chromium-free tartaric-sulfuric acid anodizing (TSA). ${ }^{1-3}$ The anodization with tartaric acid has been proven to enhance corrosion resistance, ${ }^{2}$ and increases paint adhesion without a negative effect on the fatigue resistance compared to other acidic mixtures. ${ }^{4}$ The key technical requirements for the anodizing process of aluminum are fulfilled with TSA by which homogeneous porous oxide layers with morphologies close to those produced in CAA treatments are obtained. ${ }^{5}$ Nevertheless, pre-anodized parts without good sealing or painting are not effectively protected against corrosion. The layer of aluminum oxide formed during anodizing is highly porous and is not an efficient barrier. ${ }^{3}$ Therefore, as a standard procedure to reduce porosity, anodized parts are post-treated with sealing ${ }^{3}$ or painting. ${ }^{6}$ While the TSA anodizing process was found successful in forming consistent oxide layers, the subsequent step of sealing of pores still needs technical improvements.

Up to now, hot water sealing (HWS) is the most commonly used method to improve corrosion resistance of anodized aluminum., It promotes the hydration of the porous and barrier layers of the anodic oxide followed by a volume increase, and which seals the pore channels. However, the sealing along the pore is not uniform, when the top of the pore is sealed water can no longer pass through the pore, thus the innermost sections are only partially sealed. ${ }^{8}$ Besides this drawback, the 
HWS provides only barrier protective properties. To add active corrosion-inhibiting properties to the sealing layer, mainly $\mathrm{Cr}(\mathrm{vI})$-containing solutions, such as Henkel Alodine ${ }^{\circledR} 1200{ }^{3}$ have been employed at industrial level. Therefore, there is an urgent demand to replace the toxic $\mathrm{Cr}(\mathrm{vI})$ with less harmful alternatives that meet the standard corrosion resistance requirements and the extreme conditions experienced during the on-duty life of aircrafts. Many alternative candidates are found in literature including $\mathrm{Cr}(\mathrm{III})$ among others, ${ }^{9}$ but their performance still do not match that of $\mathrm{Cr}(\mathrm{vI})$.

Li-Al-LDH structures intercalated with a corrosion inhibitor are proposed as a new integrated approach for sealing TSA treated AA2024 (Fig. 1) and a promising candidate to replace harmful $\mathrm{Cr}(\mathrm{vI})$-based sealing. This work follows previous encouraging results reported with $\mathrm{Zn}-\mathrm{Al}-\mathrm{LDH}$ on bare, ${ }^{\mathbf{1 0 - 1 2}}$ TSA treated AA2024-T3 (ref. 13) and PEO coated substrates. ${ }^{\mathbf{1 4}}$ In these works a multi-level protection was explored with $\mathrm{LDH}$ working as (1) physical barriers to seal the pores (passive protection) and also "smart" ion-exchanger providing synergistic active corrosion protection. The latter is achieved via (2) on demand controlled release of corrosion inhibitors, together with (3) absorption/entrapping of corrosive ions (e.g. $\mathrm{Cl}^{-}, \mathrm{SO}_{4}{ }^{2-}$, $\mathrm{OH}^{-}$). However, $\mathrm{Zn}-\mathrm{Al} \mathrm{LDH}$ is growing on $\mathrm{Al}$ substrates only at relatively high temperature, close to water boiling point. This fact implies important technological limitations and reduces economic feasibility of the process for many applications.

The protection properties of $\mathrm{Li}-\mathrm{Al}-\mathrm{LDH}$ clay-type conversion coatings have been proposed in the 1990s by Buchheit et al. ${ }^{15}$ not only on AA2024, but also on other aluminum alloys such as AA1100, AA6061 and AA7075. Additionally, more recently Visser et al. have studied paint systems loaded with Li-based pigments which are able to release $\mathrm{Li}$-cations to facilitate in situ formation of a LDH layer in the coating defect on AA2024 unclad TSA treated plates. ${ }^{16,17}$ The remarkable results of standard salt spray test shed light on the high potential of $\mathrm{Li}-\mathrm{Al}-\mathrm{LDH}$ as protective conversion coatings. The formation of $\mathrm{Li}-\mathrm{Al} \mathrm{LDH}$ in the defects during the corrosion tests was suggested to be the main active corrosion protection mechanism of the coatings with Li salts as anti-corrosion pigments. Moreover, the demonstrated results suggest that $\mathrm{Li}-\mathrm{Al} \mathrm{LDH}$ can be formed at relatively low temperature in a short time when Li cations are present in the solution. This fact has triggered the idea that Li-based LDH can be a better alternative for sealing porous anodic layers in comparison to $\mathrm{Zn}-\mathrm{Al}$ counterpart.

Li-Al-LDH system has unique intercalation properties, distinct from those of $\mathrm{M}^{2+}-\mathrm{M}^{3+} \mathrm{LDH}$, mainly caused by the high

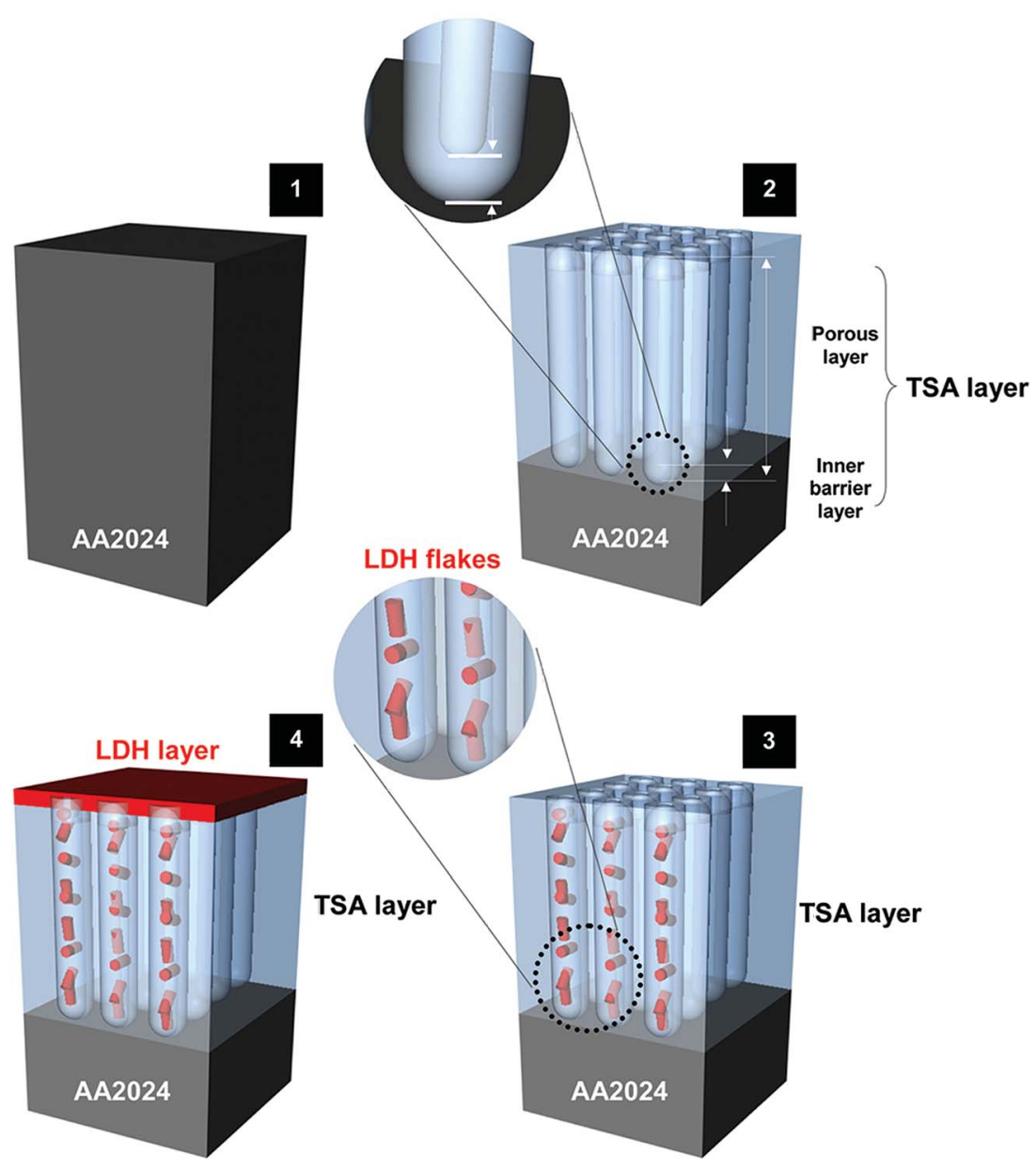

Fig. 1 Schematic representation of the TSA layer formation and LDH sealing process. 
flexibility of its hydroxide layers resembling those found in graphite materials. ${ }^{18}$ Those intercalation properties are referred to (1) a wider variety of intercalation of inorganic and organic guests such as corrosion inhibitors ${ }^{\mathbf{1 8 - 2 0}}$ and (2) staging behavior in the anion-exchange intercalation reactions, which is a rare example of this phenomenon in hydrotalcite-type minerals. ${ }^{18}$ The staging means that it is possible to have two different anion guests in the same host lattice. Additionally, the amount of the first and second guests in the host can be set using stoichiometric amounts of each guest during the first- and second-stage intercalation reaction. ${ }^{18}$

This work focuses on the optimization of the synthesis and intercalation routes of $\mathrm{Li}-\mathrm{Al}-\mathrm{LDH}$ sealing of TSA treated AA2024. Process parameters such as $\mathrm{pH}$ and temperature of the bath were thoroughly evaluated to understand their influence on morphology and corrosion performance of the sealed TSA coatings. Electrochemical impedance spectroscopy was used to evaluate the barrier and active properties of the LDH sealing loaded with corrosion inhibiting $\mathrm{VO}_{x}$ species. The localized scanning vibrating electrode technique gave information about the kinetics of corrosion processes in confined artificial defects. Formation of the passivation layer on defects mediated by the releasing of the vanadate inhibitor is discussed based on local EDX and Raman measurements. Overall, data sheds light on the corrosion protection of TSA treated AA2024 achieved through a cost-effective new environmentally friendly sealing process that can be run at room temperature and it is highly competitive with other current reference solutions, such as hot water sealing, here also studied for comparative purposes.

\section{Experimental section}

\subsection{Materials}

Panels of 2024-T3 aluminum alloy with the following composition were used as substrates: $\mathrm{Cu} 3.8-4.9 \mathrm{wt} \%, \mathrm{Mg} 1.2-1.8 \mathrm{wt} \%$, Mn 0.3-0.9 wt \%, Fe 0.5 wt\%, Si 0.5 wt\%, Zn 0.25 wt\%, Ti 0.15 wt $\%$, Cr 0.1 wt $\%$, other 0.15 wt $\%$, balance Al.

All chemicals used in the current work are of analytical grade: lithium nitrate $\left(\mathrm{LiNO}_{3}, \geq 99.5 \%\right.$, Carl Roth), sodium nitrate $\left(\mathrm{NaNO}_{3}, \geq 99 \%\right.$, Merck), sodium hydroxide $(\mathrm{NaOH}$, $\geq 99 \%$ Merck), sodium vanadium oxide $\left(\mathrm{NaVO}_{3}, 96 \%\right.$, Lancaster Synthesis), sodium chloride ( $\mathrm{NaCl}, \geq 99.8 \%$, Sigma-Aldrich), DLtartaric acid ( $\geq 99 \%$, Sigma-Aldrich), sulfuric acid $\left(\mathrm{H}_{2} \mathrm{SO}_{4}, 95-\right.$ 98\%, Alfa Aesar).

\subsection{Tartaric-sulfuric acid anodizing of AA2024-T3}

Prior to anodizing, AA2024-T3 panels $\left(8 \times 2 \mathrm{~cm}^{2}\right)$ were treated with standard commercial procedures, including degreasing, cleaning and chemical etching steps, as described in detail previously. ${ }^{13}$ The pre-treatment of the surface was followed by an anodizing process (blank panels) in a tartaric $(0.53 \mathrm{M}$ $\left.\mathrm{C}_{4} \mathrm{H}_{6} \mathrm{O}_{6}\right)$-sulfuric acid $\left(0.46 \mathrm{M} \mathrm{H}_{2} \mathrm{SO}_{4}\right)$ bath (TSA) at $37{ }^{\circ} \mathrm{C}$, with a voltage of $14 \mathrm{~V}$ for 25 min to obtain an anodic coating thickness of $3 \mu \mathrm{m}$. Following the treatment, panels were rinsed in deionized water and dried in ambient conditions.

\subsection{Sealing of TSA treated AA2024-T3}

The standard sealing of the anodized panels was accomplished by hot-water sealing (HWS, Reference panels), where samples were immersed in boiling deionized water for $30 \mathrm{~min}$, followed by a drying step in ambient conditions.

Li-Al-LDH sealing of the TSA anodized AA2024 panels was achieved by a conversion process. $\mathrm{LDH}$ structures form inside the pores of the anodic aluminum oxide layer by a surface reaction of the $\mathrm{Al}^{3+}$ cations from the oxide and the $\mathrm{Li}^{+}$containing from the treatment bath. The AA2024-T3 substrates were immersed in a $200 \mathrm{ml}$ bath mixture of $\mathrm{LiNO}_{3}(0.1 \mathrm{M})$ and $\mathrm{NaNO}_{3}(0.6 \mathrm{M})$. The treatment time of $30 \mathrm{~min}$ and magnetic stirring at $420 \mathrm{rpm}$ were constant throughout the set of growth runs. The $\mathrm{pH}$ and temperature of the bath were varied in the range of $\mathrm{pH}$ 9-12 and 25-95 ${ }^{\circ} \mathrm{C}$, respectively, to evaluate their effects on the $\mathrm{LDH}$ formation. The $\mathrm{pH}$ was adjusted using a $\mathrm{NaOH}(0.05 \mathrm{M})$ solution added drop-wise to the solution while continuously stirred. Afterwards, the samples, here referred to $\mathrm{LDH}-\mathrm{NO}_{3}$ or $\mathrm{LDH}-\mathrm{OH} /$ $\mathrm{CO}_{3}$ (according to the $\mathrm{pH}$ used), were washed with deionized water and left to dry at ambient conditions.

To prepare LDH loaded with vanadate anion species ( $\mathrm{LDH}-$ $\left.\mathrm{VO}_{x}\right)$, a solution of $\mathrm{NaVO}_{3}(0.1 \mathrm{M})$ was used at a fixed $\mathrm{pH}$ of 8.4. The range of $\mathrm{pH} \mathrm{8-9}$ is typical for obtaining oligovanadates species $\left(\mathrm{V}_{2} \mathrm{O}_{7}{ }^{2-}\right)$ which with corrosion inhibiting properties ${ }^{\mathbf{2 1 , 2 2}}$ are smaller in size for an easier intercalation in the $\mathrm{LDH}$ galleries compared to more complex polyoxovanadates. Samples were immersed in this solution $(200 \mathrm{ml})$ at $50{ }^{\circ} \mathrm{C}$ for $30 \mathrm{~min}$ while stirred at $200 \mathrm{rpm}$ to obtain a complete anionexchange of the $\mathrm{NO}_{3}{ }^{-}$or $\mathrm{OH}^{-} / \mathrm{CO}_{3}{ }^{2-}$ by $\mathrm{VO}_{x}{ }^{-}$species. Finally, samples were cleaned again as described above.

\subsection{Characterization techniques}

Glancing angle X-ray diffraction (GAXRD). Glancing angle Xray diffraction (GAXRD) was used to assess the phase composition of the sealing layers using a PANalytical X'Pert powder diffractometer at room temperature working in parallel beam mode with a CuK $\alpha$ radiation $(\lambda=0.15418 \mathrm{~nm})$, with an incident angle of $2^{\circ}$, step size of $0.01^{\circ}$ and dwell time of $15 \mathrm{~s}$.

Scanning electron microscopy (SEM). Scanning electron microscopy (SEM) was used to examine in planar-view the morphology of the prepared sealing layers. A Tescan Vega3 SB equipped with an energy dispersive X-ray (EDX) spectrometer operated at $10 \mathrm{kV}$ with a working distance of $5 \mathrm{~mm}$ was used.

Analytical transmission electron microscopy (TEM). Analytical transmission electron microscopy (TEM) was conducted on cross sections of the layers prepared using focused ion beam (FIB) milling with a FEI Helios NanoLab 600 Dual-Beam FIB/ SEM. To prevent samples damage, the surface was protected with a $300-500 \mathrm{~nm}$ Pt layer prior to FIB processing. The samples were mounted on $\mathrm{Cu}$ grids for TEM analyses. A FEI CM200 TEM equipped with EDX spectrometer was used at an operating voltage of $200 \mathrm{kV}$.

Glow discharge optical emission spectroscopy (GDOES). Glow discharge optical emission spectroscopy (GDOES) depth profile analyses of the layers were conducted in a HORIBA GDProfiler 2 (anode of $4 \mathrm{~mm}$ in diameter, at $650 \mathrm{~Pa}$ and $30 \mathrm{~W}$ ). 
Confocal Raman microscopy. Confocal Raman microscopy (Bruker, Senterra II) was utilized to perform localized point analyses of the phase composition of the AA2024 panels before and after immersion in $0.05 \mathrm{M} \mathrm{NaCl}$, at the LDH layers and artificial scribe. Spectra were collected at $532 \mathrm{~nm}$ with a constant laser power of $50 \mathrm{~mW}$, aperture of $50 \mu \mathrm{m}, 128$ scans and $3 \mathrm{~s}$ of integration time.

Electrochemical impedance spectroscopy (EIS). Electrochemical impedance spectroscopy (EIS) was conducted at room temperature using a three-electrode cell assembly with a platinum electrode as the counter electrode, coated AA2024 electrode as the working electrode (exposed area of $0.5 \mathrm{~cm}^{2}$ ) and a saturated calomel electrode as the reference electrode. An aqueous solution of $0.05 \mathrm{M} \mathrm{NaCl}(350 \mathrm{ml})$ was used as the electrolyte. To avoid the interference from external electromagnetic fields all tests were performed inside a Faraday cage. The measurements were done using a Gamry Reference 600 potentiostat/galvanostat/ ZRA at different immersion times up to 1 month. A frequency range from $10^{5}$ to $10^{-2} \mathrm{~Hz}$, with a sinusoidal perturbation of $10 \mathrm{mV}$ rms vs. open circuit potential (OCP), with 9 points per frequency decade was used. At least two replicates were acquired showing good reproducibility. The impedance spectra were analyzed with ZView software, the goodness of fit of the simulated spectra corresponded to chi-squared values of $<0.01$. The errors for the individual parameters of the equivalent electrical circuits, such as CPE and $R$, were $<5 \%$.

Scanning vibrating electrode technique (SVET). Scanning vibrating electrode technique (SVET) measurements were performed using Applicable Electronics Inc. (USA) instrumentation controlled with the ASET-LV4 software from ScienceWares (USA). The Pt/Ir vibrating microelectrode was platinized to form a platinum black tip of $15 \pm 3 \mu \mathrm{m}$ diameter. It vibrated with $30 \mu \mathrm{m}$ amplitude in two orthogonal directions (normal and parallel to the sample surface) and was placed at $100 \pm 3 \mu \mathrm{m}$ above the sample. All samples were tested in a $0.05 \mathrm{M} \mathrm{NaCl}$ solution. This concentration was kept quasi constant by using a communicating vessels system. The SVET cell containing $10 \mathrm{ml}$ of the electrolyte was kept in contact with a vessel of $150 \mathrm{ml}$ filled with the same $0.05 \mathrm{M} \mathrm{NaCl}$ electrolyte. Local current maps were recorded every hour during 2 full days. Two samples of each type were tested to ensure reproducibility. To accelerate corrosion and quickly evaluate the active protection properties of LDH layers, the artificial defects were made on their surfaces (two holes with a diameter of $100 \mu \mathrm{m}$ each, spaced at $1 \mathrm{~mm}$ and a scribe of 1.5 $\mathrm{mm}$ length and $35 \mu \mathrm{m}$ width between the two holes). Origin 9.1 software was used to plot the SVET maps.

\section{Results and discussion}

\subsection{Optimization of LDH sealing bath conditions}

In previous work, $\mathrm{Zn}$-Al-LDH sealing was successfully achieved on TSA-AA2024 at $95{ }^{\circ} \mathrm{C}$ under an optimized $\mathrm{pH}$ conditions. ${ }^{13} \mathrm{~A}$ similar strategy was used to perform Li-Al-LDH sealing in this investigation. The temperature was fixed at $95{ }^{\circ} \mathrm{C}$, while the $\mathrm{pH}$ was varied to find the best condition to precipitate $\mathrm{Li}-\mathrm{Al}-\mathrm{LDH}$. According to previous reports, ${ }^{\mathbf{1 5 , 2 3 , 2 4}}$ both homogeneous $\mathrm{Li}-\mathrm{Al}$ $\mathrm{LDH}-\mathrm{CO}_{3}$ and $\mathrm{Li}-\mathrm{Al}-\mathrm{LDH}-\mathrm{NO}_{3}$ layers formed on $\mathrm{Al}$ alloys when the reactants involved $\left(\mathrm{Al}^{3+}\right.$ and $\left.\mathrm{Li}^{+}\right)$were in high concentrations to cause the co-precipitation in the $\mathrm{LDH}$ structure form. The $\mathrm{pH}$ condition for this to occur was above 10 .

Fig. 2 shows the appearance and SEM micrographs of the TSA and $\mathrm{LDH}$ sealed samples for different $\mathrm{pH}$ conditions. Overall, panels are relatively uniform in color (Fig. 2a, d, g, j, $\mathrm{m}$ and p) and are completely covered with a LDH layer, as observed in the SEM micrographs at low magnification (Fig. 2b, e, h, k, n and q). At this magnification, it can also be seen that all samples show pitlike defects with size in the range of 5-10 $\mu \mathrm{m}$, typical of TSA treated surfaces (Fig. 2b). These defects are formed in the initial stages of etching of the bare alloy, with finer defects being related to the preferential etching of the second phase materials. ${ }^{25,26}$ It is evident from the data that $\mathrm{pH}$ plays an important role in the dissolution rate of the TSA anodic layer and formation of $\mathrm{LDH}$ structures. The thickness of the LDH layers (Fig. 2b, e, h, k, n and q), and the size and density of LDH flakes (Fig. 2c, f, i, e, o and r) decrease with $\mathrm{pH}$ increase. SEM images of the cross-sectional view of the samples were used to measure the thickness of the

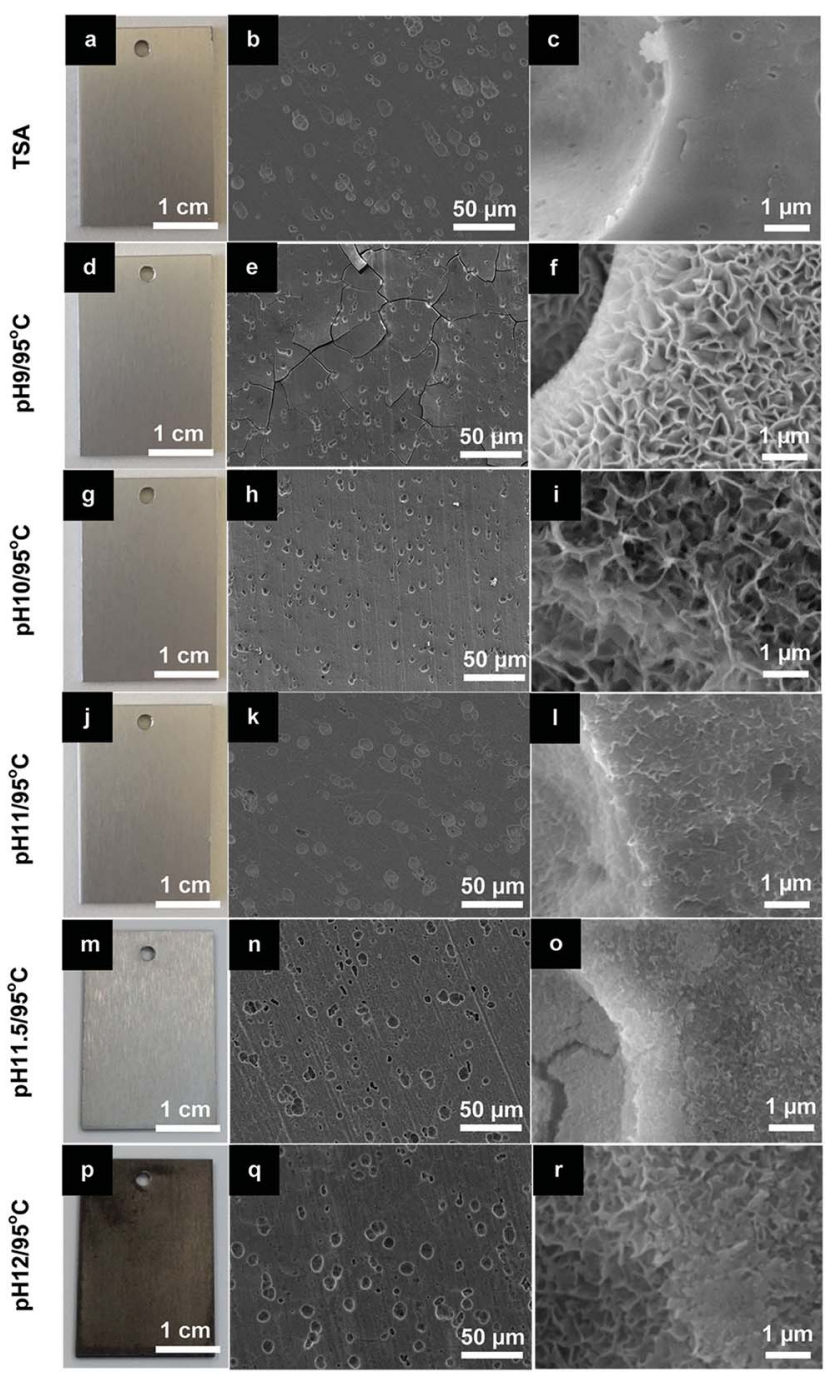

Fig. 2 Photographs and SEM images of (a-c) TSA (blank sample) and $\mathrm{LDH}$ sealed TSA at $95^{\circ} \mathrm{C}$ under different $\mathrm{pH}$ conditions: (d-f) pH 9; (gi) $\mathrm{pH} 10$; (j-l) $\mathrm{pH} 11$; (m-o) $\mathrm{pH} 11.5$ and $(\mathrm{p}-\mathrm{r}) \mathrm{pH} 12$. 
layers (data not shown). At $\mathrm{pH}$ 11, the LDH particles still have a flake-like morphology and a high density of nano sized LDH flakes is observed. These two characteristics together with a thin LDH layer $(\sim 1 \mu \mathrm{m})$ leads to a perfect mimicking of the topography of the TSA substrate without formation of cracks (Fig. $2 b$ and k), as those seen at pH 9 (Fig. 2e) due essentially to higher thickness $(\sim 2.2 \mu \mathrm{m})$. At more alkaline conditions, above $\mathrm{pH} 11$, the dissolution of the TSA layer becomes too fast. A well defined attack of the surface is seen together with an increased darkening of the sample which is related to dissolution of the substrate and formation of Cu-containing smut.

The XRD patterns of the samples are shown in ESI Fig. S1 (please see ESI $\dagger$ ). For LDH layers typically grown for $30 \mathrm{~min}$, as described in Section 2.3, the thickness of the layers is too low and results in peak broadening with lower peak intensity (ESI Fig. S1a $\dagger$ ). But longer growth runs for 5 hours were also prepared as model experiments to improve the XRD signal and help on the discussion of differences between samples (ESI Fig. S1a $\dagger$ ). The XRD analyses illustrate the presence of crystalline LDH structures with typical $\mathrm{Li}-\mathrm{Al}-\mathrm{LDH}-\mathrm{NO}_{3}$ reflections (002), (101) and (004) at $9.88^{\circ}\left(d_{(002)}=8.95 \AA\right), 20.21^{\circ}\left(d_{(101)}=4.39 \AA\right)$ and $23.18^{\circ}\left(d_{(004)}=\right.$ $3.84 \AA$ ) , respectively, for samples prepared at $\mathrm{pH} 9 / 95^{\circ} \mathrm{C}$ and $\mathrm{pH}$ $10 / 95{ }^{\circ} \mathrm{C}$ (ESI Fig. S1a $\dagger$ ), in accordance with previous reports. ${ }^{27-29}$ For more alkaline aqueous baths, above $10 \mathrm{pH}$, in ambient atmosphere conditions, $-\mathrm{OH}^{-}$and $-\mathrm{CO}_{3}{ }^{2-}$ anions are the predominant species ${ }^{15,30}$ and compete with $-\mathrm{NO}_{3}{ }^{-}$to preferentially form $\mathrm{LDH}-\mathrm{OH}$ or $\mathrm{LDH}-\mathrm{CO}_{3}$ structures. ${ }^{31,32}$ At $\mathrm{pH} 11$ the peak positions for reflections (002), (101) and (004) shift to higher angles at $11.62^{\circ}\left(d_{(002)}=7.6 \AA\right), 20.40^{\circ}\left(d_{(101)}=4.35 \AA\right)$ and $23.32^{\circ}$ $\left(d_{(004)}=3.81 \AA\right)$, respectively. This is ascribed to $\mathrm{LDH}-\mathrm{OH} / \mathrm{CO}_{3}$ signature, showing that $\mathrm{LDH}$ are intercalated with $-\mathrm{OH}^{-} / \mathrm{CO}_{3}{ }^{2-}$, with similar crystallinity than $\mathrm{LDH}-\mathrm{NO}_{3}$ structures..$^{2,30-32}$ Other secondary phases such as $\mathrm{Li}_{2} \mathrm{CO}_{3}$ (ref. 27) and $\mathrm{Al}(\mathrm{OH})_{3}$ (ref. 24) were also detected.

To evaluate the influence of $\mathrm{LDH}$ sealing prepared at different $\mathrm{pH}$ on the final corrosion behavior of samples, EIS measurements up to one week of immersion in $0.05 \mathrm{M} \mathrm{NaCl}$ aqueous solution were performed (Fig. 3). Among the several pH conditions, by far the best sealing and protection performance were obtained for the $\mathrm{pH} 11 / 95^{\circ} \mathrm{C}$ condition. After 1 week of immersion (Fig. 3b), this sample demonstrates the highest modulus of impedance values in the whole frequency range, more than one order of magnitude higher than all the other $\mathrm{pH}$ conditions, and almost three orders of magnitude higher than the TSA (blank sample). It is also interesting to note that the sample prepared at pH 11.5 also increased the resistance of the porous layer in comparison to the $\mathrm{pH}$ below 11 . One possible reason could be attributed to the higher performance of $\mathrm{LDH}-\mathrm{OH} / \mathrm{CO}_{3}$ type materials, formed above $\mathrm{pH} 10$, over the $\mathrm{LDH}-\mathrm{NO}_{3}$ ones. But this is far too difficult to further understand the mechanisms based only on EIS analyses. Moreover, the crystallinity of the LDH structures seems not playing a relevant role in the resistance of the layers since all prepared samples have similar crystallinity. The most plausible reason for the superior properties of the $\mathrm{LDH}$ sealing at $\mathrm{pH} 11 / 95{ }^{\circ} \mathrm{C}$ is related to the lower layer thickness which is free of cracks combined with a very uniform densely packed at nano-scale LDH flakes (Fig. 2k and l).
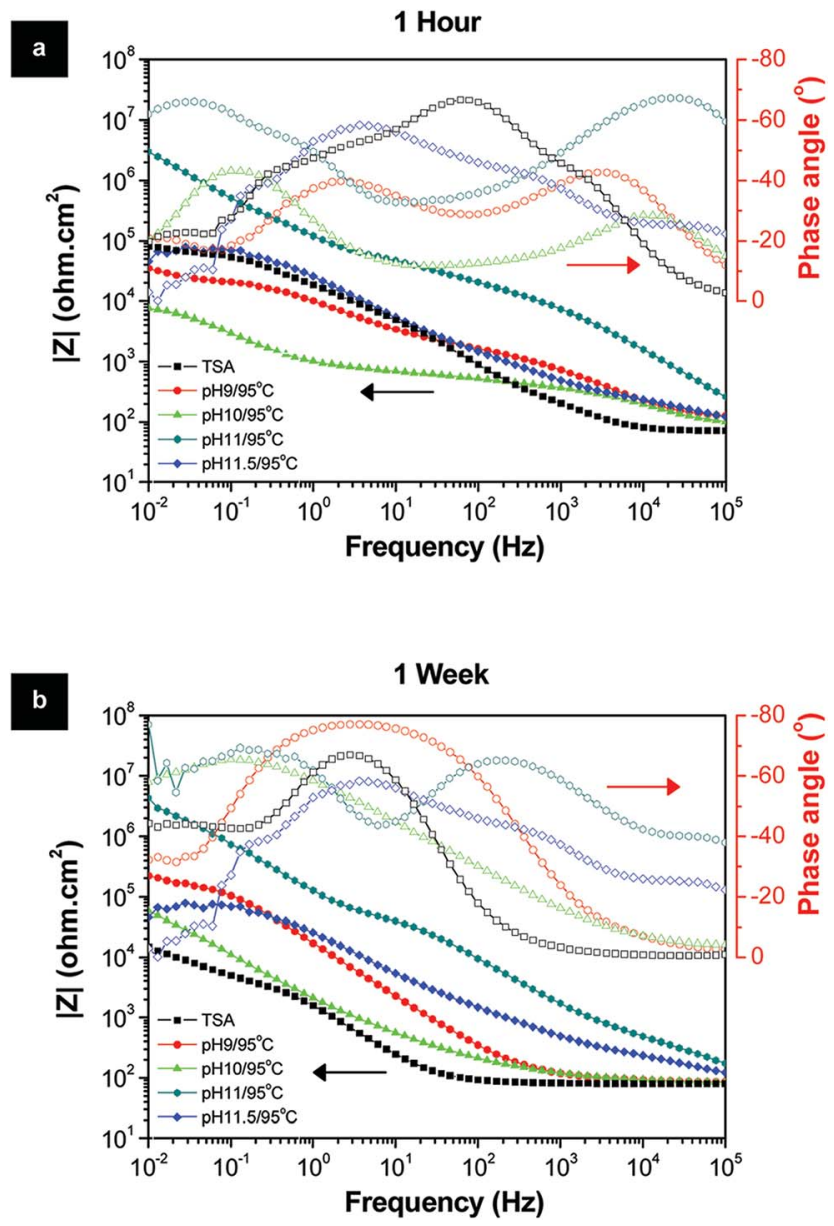

Fig. 3 Bode and phase angle plots of the LDH layers prepared at different $\mathrm{pH}$ after (a) 1 hour and (b) 1 week immersion in $0.05 \mathrm{M} \mathrm{NaCl}$ solution.

TEM analyses (Fig. 4) of the cross-sectional view of the layers sheds some light on the LDH flakes structure inside the nanosized porosity of the TSA layer. LDH flakes hierarchically organized in size are seen, bigger on the surface (Fig. 4a) and with decreased size down to nanometer scale partially inside the pores (Fig. 4b). Images give clues for flakes of $\sim 40 \mathrm{~nm}$ been growing in an entangled form partially inside the pores of $\sim 90 \mathrm{~nm}$ together with a partial conversion of the anodic layer into $\mathrm{LDH}$ structures. Although, it is not clear in Fig. $4 \mathrm{~b}$ to which extend in deep inside the pore the LDH growth occurred.

Results point out that the high anti-corrosive performance of the $\mathrm{pH} 11 / 95^{\circ} \mathrm{C}$ sample might not be only due to the good barrier properties of the densely packed LDH top layer of $\sim 1 \mu \mathrm{m}$, but also from the LDH nano-flakes partially sealing the pores.

\subsection{Active sealing with $\mathrm{VO}_{x}$ intercalated LDH}

The best growth condition for $\mathrm{LDH}\left(\mathrm{pH} \mathrm{11/95}{ }^{\circ} \mathrm{C}\right.$ ) found in previous Section 3.1 provides good barrier properties. This method of $\mathrm{LDH}$ preparation was further improved to include active corrosion. To this end, inhibitor was incorporated in $\mathrm{LDH}$ nano-flakes by preparing $\mathrm{LDH}$ intercalated with $\mathrm{VO}_{x}, \mathrm{LDH}-\mathrm{VO}_{x}$. 

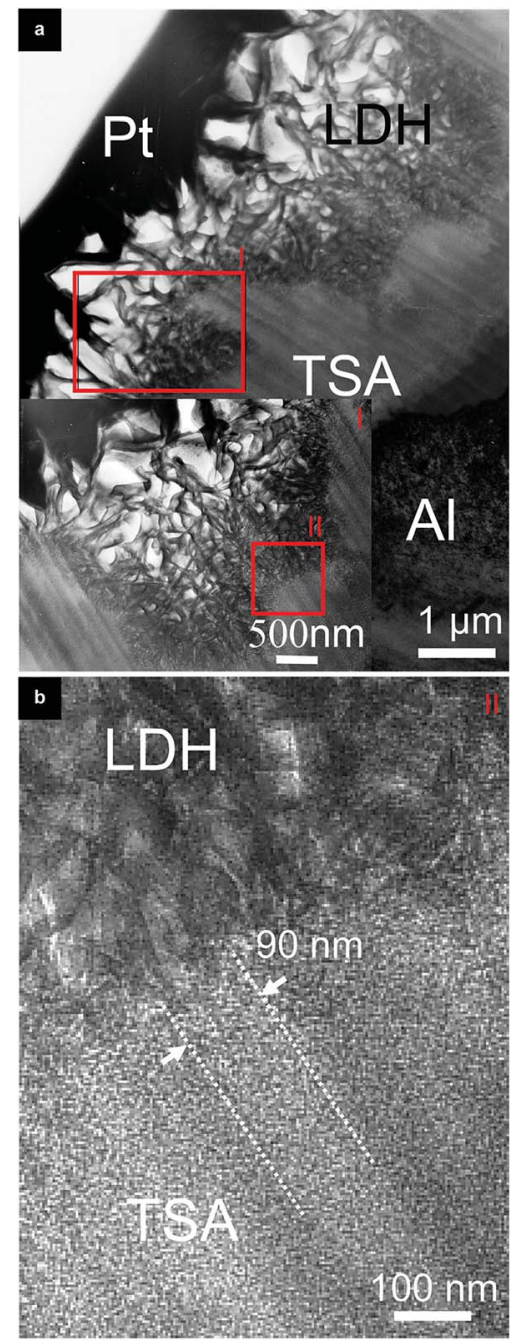

Fig. 4 TEM images of the $\mathrm{LDH}$ sealing layer prepared at $\mathrm{pH} 11 / 95^{\circ} \mathrm{C}$. (a) Low-magnification image of the cross-sectional view of the layer and (b) high-magnification image of nano-sized LDH flakes formed inside the nanostructured pores of the TSA porous layer.

ESI Fig. S2a and $\mathrm{b} \dagger$ present the low magnification TEM images of $\mathrm{LDH}-\mathrm{OH} / \mathrm{CO}_{3}$ and $\mathrm{LDH}-\mathrm{VO}_{x}$ samples showing very uniform LDH layers (easily seen at higher magnification in the corresponding inset images). The respective EDX spectra presented in ESI Fig. S2c and d $\dagger$ clearly highlight the presence of the vanadium in the $\mathrm{LDH}-\mathrm{VO}_{x}$ samples, as expected. Moreover, to show that the $\mathrm{VO}_{x}$ species were intercalated in the $\mathrm{LDH}$ galleries and not adsorbed on its surface, diffraction patterns were analyzed (inset images of ESI Fig. S2a and $b \dagger$ ). Both materials have diffraction patterns with well-defined rings typical of LDH structures. ${ }^{33}$ The $d$-spacings calculated from the rings diameters of $(h k l)$ type planes corresponding to the $c$ stacking direction, related to $\mathrm{LDH}$ galleries height, increased with the intercalation of the $\mathrm{VO}_{x}$ species from $d_{(442)}=1.76 \AA$ $\left(\mathrm{LDH}-\mathrm{OH} / \mathrm{CO}_{3}\right)$ to $d_{(442)}=1.86 \AA\left(\mathrm{LDH}-\mathrm{VO}_{x}\right)$, due to the increased radius of the anion or/and decrease in charge density in relation to $\mathrm{OH}^{-} / \mathrm{CO}_{3} \cdot{ }^{2-31}$ The respective XRD patterns of the samples (ESI Fig. S3†) corroborate the TEM analyses, a slight

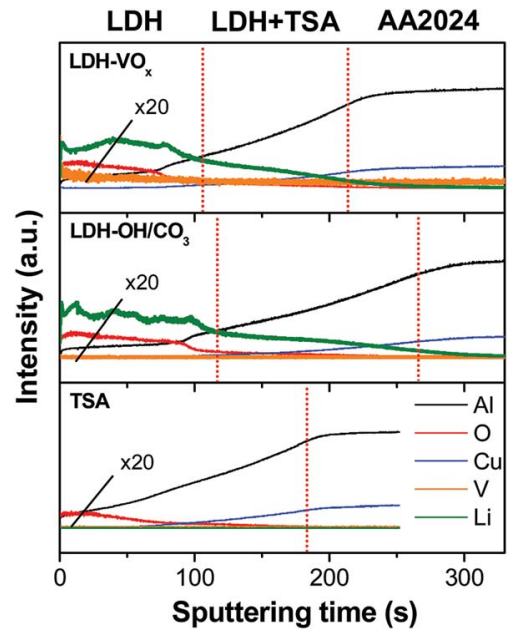

Fig. 5 GDOES depth profiles of the TSA (blank sample) and LDHbased layers.

shift of $0.08^{\circ}$ of the (002) peak to lower angles was observed when $\mathrm{VO}_{x}$ species were intercalated in $\mathrm{LDH}$, in agreement with other works published by the authors. ${ }^{\mathbf{1 3 , 1 4}}$ These results highlight that the $\mathrm{VO}_{x}$ species are inside the host $\mathrm{LDH}$ galleries and a successful intercalation process was achieved. ${ }^{28,31,34}$

GDOES depth profiles of the samples shown in Fig. 5, indicate that the lithium and vanadium signals are observed preferentially both at the TSA surface and also deeper, within the pores, giving clue that might almost reach the oxide/metal interface. These results corroborate the TEM observations (Fig. 4) and provide evidences for a partially sealing in depth with LDH structures carrying active corrosion inhibiting species inside the pores for an improved synergetic corrosion protection: barrier properties and active inhibition.

\subsection{Benchmarking studies of sealing processes}

As referred in the Introduction section, HWS is the state-of-theart sealing applied in aeronautics. HWS is used here as a reference to compare with the new LDH-based sealing processes. Photographs and SEM images of the Li-Al-LDH samples (ESI Fig. S4 $\dagger$ ) show that the clean surface appearance and the flakelike structures are very similar to the reference and are in good agreement with the previous report. ${ }^{15}$

The EIS measurements, for long immersion time up to 1 month, in Fig. 6 show that the $\mathrm{VO}_{x}$ species have a positive effect on the barrier properties of the TSA layer, both resistances of the inner and porous layers illustrated in Fig. 1 are higher than those for $\mathrm{LDH}-\mathrm{OH} / \mathrm{CO}_{3}$. Previous results obtained on $\mathrm{Zn}-\mathrm{Al}-$ LDH system are consistent with the present ones. ${ }^{13}$ Moreover, the LDH sealings have higher performance when compared with the HWS ones, $R_{\text {in }}$ and $R_{\text {por }}$ of the LDH-based layers are generally higher than the HWS values over time Fig. 6 .

The superior $R_{\text {por }}$ values of the LDH-based layers over the HWS layers are explained by the existence of an extra time constant (Fig. 7). This additional relaxation process at higher frequencies for the $\mathrm{LDH}$-based layers can be ascribed to the $\mathrm{LDH}$ top layer (por 1). The second time constant at middle 
a

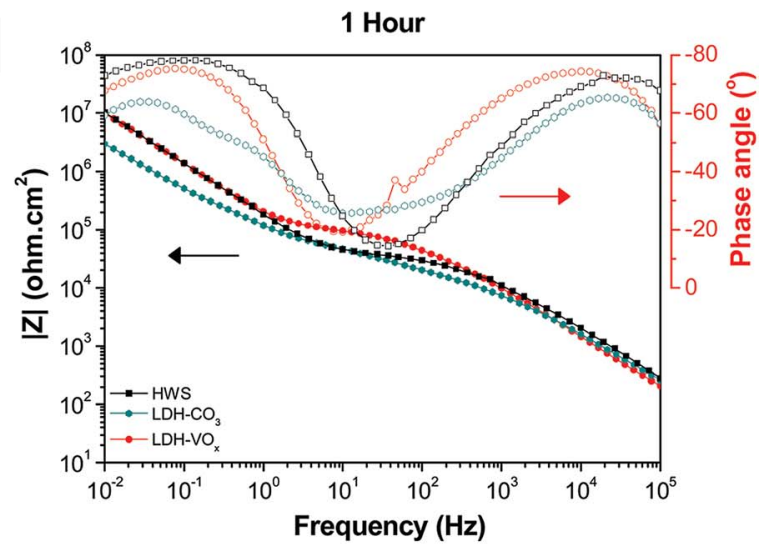

b

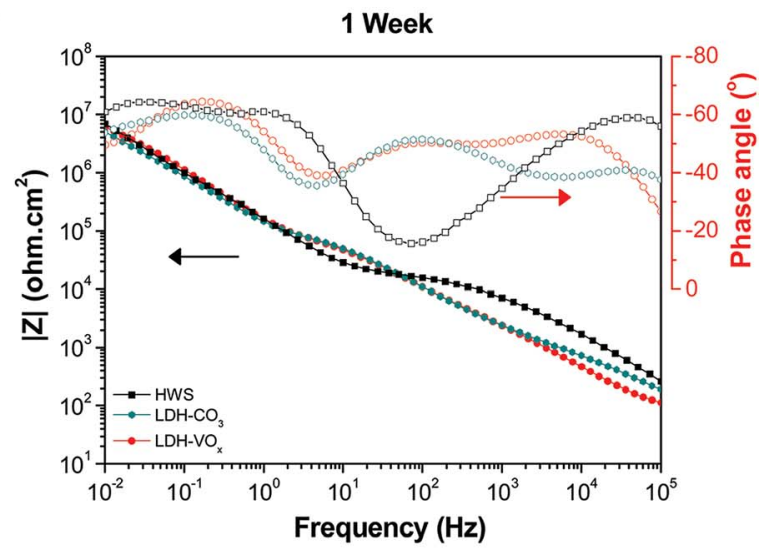

c

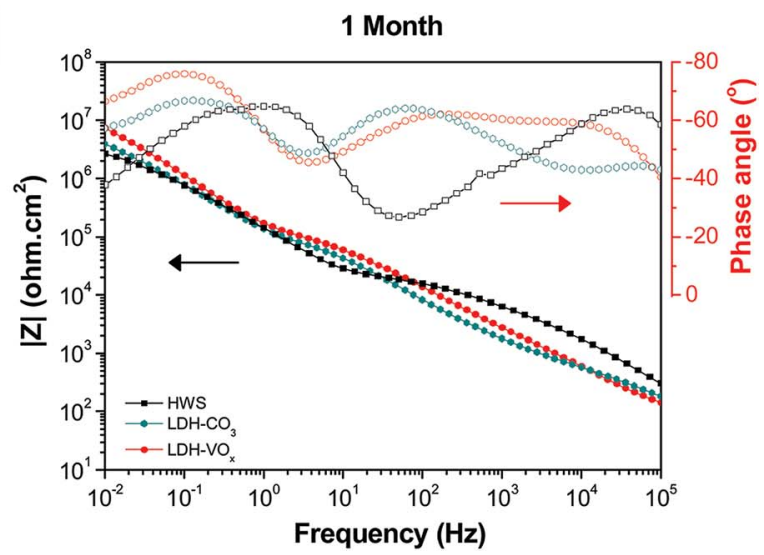

Fig. 6 Bode and phase angle plots of the HWS and LDH-based layers after (a) 1 hour, (b) 1 week and (c) 1 month immersion in $0.05 \mathrm{M} \mathrm{NaCl}$ solution.

frequencies is related to the barrier properties of the conversion layer within the porous part of TSA (Fig. 7). In the case of HWS, only one well defined time constant responsible for the sealed porous layer is observed, since there is no formation of such an extra layer on the top. The respective equivalent circuits are presented in Fig. $7 \mathrm{~b}$ and d.

The evolution of the layer parameters for different systems is presented in Fig. 8. The resistance of the pore for the porous layer sealed with LDH is represented by the sum of two components described above. The resistance of the sealed porous layer is the highest for $\mathrm{LDH}^{-\mathrm{VO}_{x}}$ followed by the one with nitrate $\mathrm{LDH}$, suggesting in both cases an efficient LDH mediated blocking of ionic transport through the layer. Even more importantly, the resistance of the inner barrier layer at the metal interface is also highest and the most stable for the inhibitor containing LDH sealed sample. This layer is the last barrier for the corrosive species before reaching the metal surface and thus plays a determining role in the total performance of the system.

It is well-know that hot-water sealing treatments promote the hydration of the porous aluminium oxide, porous and barrier layers, to produce a crystalline needle-like hydrate phase, know as boehmite, which filled in the pores. ${ }^{35}$ Similar aqueous treatments supplemented with inorganic salts, such as those used here, will have a synergetic effect of having formed a mixture of boehmite phase and new precipitated LDH phases, also with morphology resemble needle structures, growing inside the pores to form higher packed sealings. This clearly explains the superior resistance of the inner barrier layer of the LDH sealings over the HWS ones (Fig. 8). On the other hand, the higher performance of $\mathrm{LDH}-\mathrm{VO}_{x}$ compared to $\mathrm{LDH}-\mathrm{OH} / \mathrm{CO}_{3}$ is not completely comprehensible, with different contributions being valid. For $\mathrm{LDH}-\mathrm{VO}_{x}$ samples, the extra intercalation step in water might contribute to further hydration of the barrier layer. Also, the vanadate species that were not intercalated in the $\mathrm{LDH}$, and are available in solution, can be absorbed on top of the barrier layer contributing to the increase of its resistance (Fig. 8). Other possibility is assigned to the self-healing effect of the LDH sealing, i.e. release of the $\mathrm{VO}_{x}$ inhibitor and covalent bonding to the metal surface upon starting of corrosion events. ${ }^{22}$ Eventhough, this is less reasonable at significant extend, because if true EIS data of Fig. 8 would show an increase of the resistance of the inner barrier layer mediated by the release of the inhibitor. Contrarily, a decreasing behavior of resistance is observed, in line with previous observations. ${ }^{14}$ This is in agreement with the EIS of Fig. $7 \mathrm{c}$ and d, showing that the resistance of the charge transfer $\left(R_{\mathrm{ct}}\right)$ activities at the metal surface is still very high after 1 month of immersion in $\mathrm{NaCl}$. This means that the corrosion kinetic is very low, with far too small corrosion events able to activate the self-healing effect.

Therefore, SVET localized analyses at artificial defects were accomplished to further understand the corrosion processes and kinetics. The SVET observations shown in Fig. 9 corroborate the EIS data. Strong anodic activity is seen in the blank (TSA) and reference (HWS) samples after $24 \mathrm{~h}$ immersion in $0.05 \mathrm{M} \mathrm{NaCl}$, but not in the LDH treated samples. Additionally, LDH- $\mathrm{VO}_{x}$ samples have higher anticorrosive properties than $\mathrm{LDH}-\mathrm{OH} / \mathrm{CO}_{3}$ ones. This is in good agreement with previous results for $\mathrm{Zn}-\mathrm{Al}-\mathrm{LDH}$ sealing. ${ }^{13} \mathrm{After} 48 \mathrm{~h}$ of immersion, only weak cathodic activity in $\mathrm{LDH}-\mathrm{VO}_{x}$ samples was seen, while stronger anodic and cathodic activities were detected in the $\mathrm{LDH}-\mathrm{OH} / \mathrm{CO}_{3}$ samples. Also note that corrosion activity was restricted only to the artificial defects in case of $\mathrm{LDH}-\mathrm{OH} / \mathrm{CO}_{3}$ and $\mathrm{LDH}-\mathrm{VO}_{x}$ samples, while for TSA and HWS samples, with time, corrosion propagated also to the initially intact areas. For immersion times up to $48 \mathrm{~h}$, a fluctuating cathodic activity (increase and decrease) measured on the $\mathrm{LDH}^{-\mathrm{VO}_{x}}$ samples was detected, as shown for $24 \mathrm{~h}$ and $48 \mathrm{~h}$ acquisition times, that can 


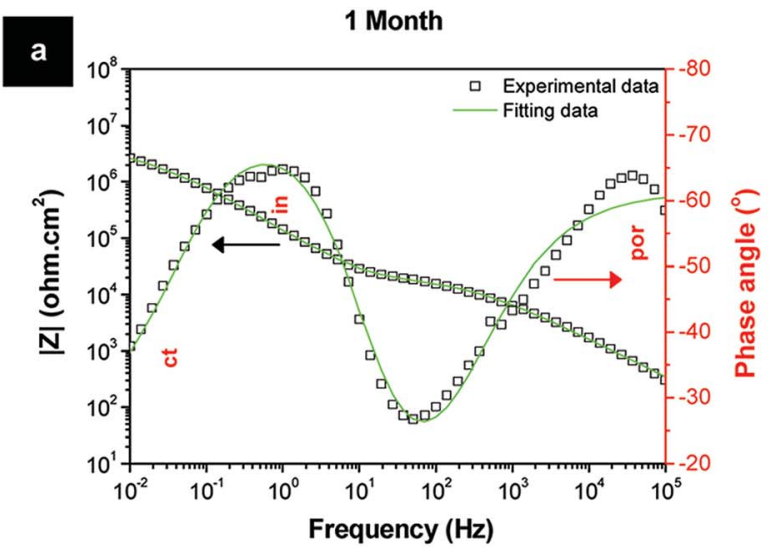

b

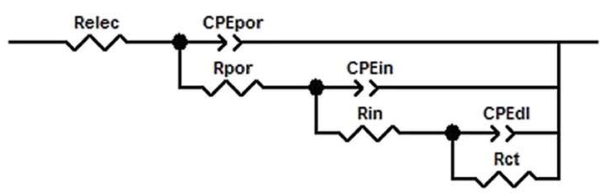

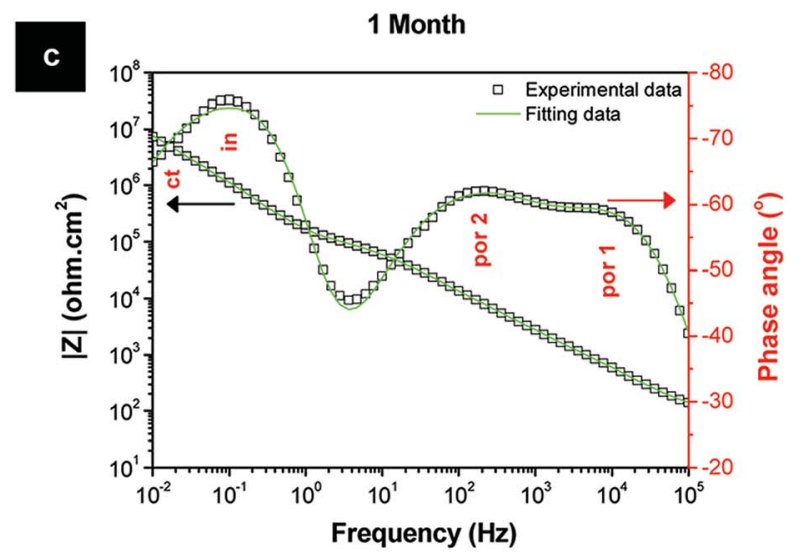

d

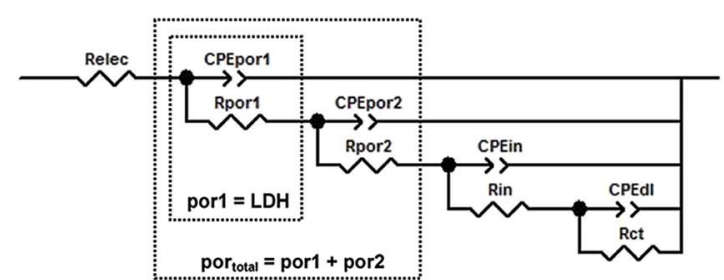

Fig. 7 Fitting data of the sealing layers for 1 month of immersion in $0.05 \mathrm{M} \mathrm{NaCl}$ and respective equivalent circuits: $(a, b) \mathrm{HWS}$ and $(c, d) \mathrm{LDH}-\mathrm{VO}$.

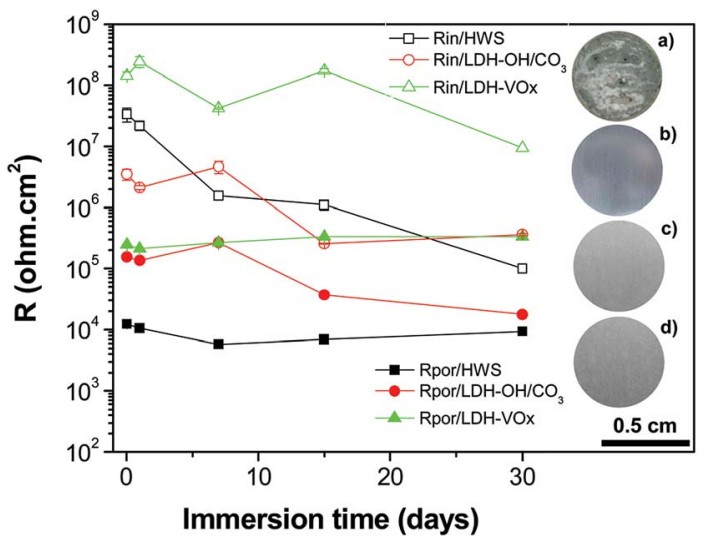

Fig. 8 Evolution over immersion time in $0.05 \mathrm{M} \mathrm{NaCl}$ of the resistance of porous and inner layers of the HWS and LDH-based samples. Photographs of samples after 1 month of immersion: (a) TSA (blank sample); (b) hot-water sealed TSA (reference sample); (c) $\mathrm{LDH}-\mathrm{OH} /$ $\mathrm{CO}_{3}$ and $(\mathrm{d}) \mathrm{LDH}-\mathrm{VO}_{x}$ sealed TSA.

be assigned to the controlled release of the inhibiting $\mathrm{VO}_{x}$ species on demand (triggered by the corrosion activities). This effect can be easily seen in Fig. S4, $\uparrow$ where an increase of the cathodic activity means that insufficient amount of $\mathrm{VO}_{x}$ species are released, but after a resting period of around $24 \mathrm{~h}$ (activation of the $\mathrm{LDH}$ release process), the $\mathrm{VO}_{x}$ species begins to be released followed by a reduction of the cathodic activity in the next $24 \mathrm{~h}$. This corroborates recent published studies on the corrosion inhibition of AA2024-T3. It was found that $\mathrm{VO}_{x}$ species inhibit cathodic kinetics of AA2024-T3 corrosion in $\mathrm{NaCl}$ solutions ${ }^{36}$ upon formation of an adsorbed passivation layer $^{21}$ that suppresses the oxygen reduction. ${ }^{22}$

Moreover, the observed behavior also shows that the $\mathrm{VO}_{x}$ species are inside the LDH galleries, otherwise, if they were adsorbed on the LDH walls, no activation time would be seen, the $\mathrm{VO}_{x}$ species would start to protect the surface immediately when the onset of the first activities occurred at the scribe, after $6 \mathrm{~h}$ of immersion in the corrosive solution (ESI Fig. S5 †).

Further investigation on the $\mathrm{VO}_{x}$ species release and delivery to the defect side was done with Raman and EDX analyses (ESI Fig. S6 and $\mathrm{S} 7 \dagger$ ). $\mathrm{LDH}-\mathrm{VO}_{x}$ samples were studied before and after immersion in $0.05 \mathrm{M} \mathrm{NaCl}$ for $48 \mathrm{~h}$, the same conditions as used for SVET tests.

Raman phase analyses were used to decipher which $\mathrm{VO}_{x}$ species play a key role in the corrosion inhibition in the defects. Optical images of the samples, before (ESI Fig. S6a $\dagger$ ) and after immersion (ESI Fig. S6c广), show that the scribe becomes dark with corrosion products after immersion in the $\mathrm{NaCl}$ corrosive medium. So, $\mathrm{VO}_{x}$ species are expected to be released from $\mathrm{LDH}$ structure and diffuse through the electrolyte towards the scribe where they suppress corrosion to some extent, accordingly to SVET data (Fig. 9 and ESI Fig. S5 †). As shown by Ribeiro et al., monovanadates $\left(\mathrm{VO}_{4}^{-}\right)$, monoprotonated monovanadates $\left(\mathrm{HVO}_{4}{ }^{2-}\right)$ and divanadates $\left(\mathrm{V}_{2} \mathrm{O}_{7}{ }^{4-}\right)$ present a broad band in the range of $790-880 \mathrm{~cm}^{-1}$, while diprotonated monovanadates $\left(\mathrm{H}_{2} \mathrm{VO}_{4}{ }^{-}\right)$and cyclic tetravanadates $\left(\mathrm{V}_{4} \mathrm{O}_{12}{ }^{4-}\right)$ have typically 

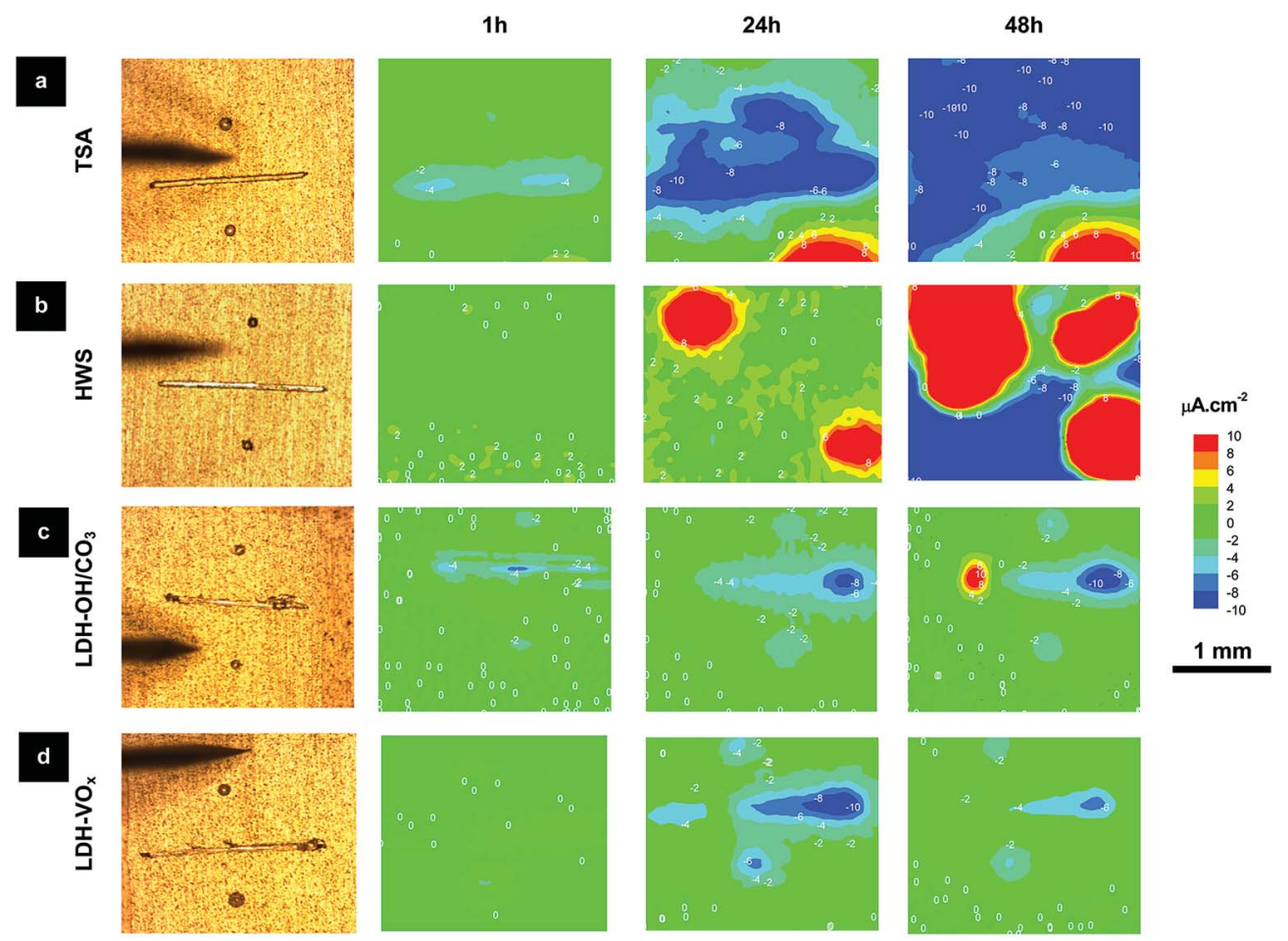

Fig. 9 Optical images and SVET maps of layers with artificial defects after $1 \mathrm{~h}, 24 \mathrm{~h}$ and $48 \mathrm{~h}$ immersion in $0.05 \mathrm{M} \mathrm{NaCl} \mathrm{solution} \mathrm{for} \mathrm{(a)} \mathrm{TSA} \mathrm{(blank}$ sample); (b) hot-water sealed TSA (reference sample); (c) $\mathrm{LDH}-\mathrm{OH} / \mathrm{CO}_{3}$ and (d) $\mathrm{LDH}-\mathrm{VO}_{x}$ sealed TSA.

a sharp asymmetric band centered at $945 \mathrm{~cm}^{-1} \cdot{ }^{37}$ All spectra of ESI Fig. S6c and $d \dagger$ show the presence of a broad band in the $790-880 \mathrm{~cm}^{-1}$ range with a sharp peak centered at $824 \mathrm{~cm}^{-1}$ that is overlapped with sharp asymmetric band at $942 \mathrm{~cm}^{-1}$. This data shows that a mixture of monovanadate species might play a role in the corrosion protection, ${ }^{15}$ perhaps with a predominance of $\mathrm{H}_{2} \mathrm{VO}_{4}{ }^{-}$or $\mathrm{V}_{4} \mathrm{O}_{12}{ }^{4-}$ species due to a more intense band signal. For the sample exposed for $48 \mathrm{~h}$ to $\mathrm{NaCl}$, the signal of the $\mathrm{VO}_{x}$ species on the scribe is below the detection limit, cannot be seen. Signals can only be seen on the $\mathrm{LDH}^{-\mathrm{VO}_{x}}$ layers, before and after immersion (ESI Fig. S6b and $d \dagger$ ).

EDX analyses shown in ESI Fig. S7 $\uparrow$ were performed to verify the presence of vanadium $(\mathrm{V})$ in the defects, and give complementary information to the obtained Raman data. ESI Fig. S7a and $c \dagger$ correspond to the SEM micrographs of the scribe before and after immersion, respectively. The EDX line acquisition conducted across the scribe shows that the $\mathrm{V} \mathrm{K}_{\alpha}$-shell signal of the $\mathrm{VO}_{x}$ species (at $4.95 \mathrm{keV}$ ) was detected on the $\mathrm{LDH}-\mathrm{VO}_{x}$ layer, but not on the scribe, as expected (ESI Fig. S7b $\dagger$ ). After $48 \mathrm{~h}$ immersion in $\mathrm{NaCl}$, the scribe (inset of ESI Fig. S7 $\dagger$ ) had a different appearance compared with a fresh scribe (inset of ESI Fig. S7a $\dagger$ ). The scribe exposed to $\mathrm{NaCl}$ contains deposited corrosion products and exposed $\mathrm{Cu}$-containing intermetallics. It is of interest to see that the localized EDX analysis on the intermetallic particle (red line, ESI Fig. S7d $\dagger$ ) shows strong $\mathrm{K}_{\alpha^{-}}$ shell signals at 5.89, 6.37 and $8.04 \mathrm{keV}$ for $\mathrm{Mn}, \mathrm{Fe}$ and $\mathrm{Cu}$, respectively, together with the appearance of the $\mathrm{V}$ signal at 4.95 $\mathrm{keV}$. According to recent studies on the corrosion inhibition of $\mathrm{AA} 2024-\mathrm{T} 3,{ }^{22,36} \mathrm{Al}-\mathrm{Cu}-\mathrm{Mn}-\mathrm{Fe}-\mathrm{Si}$ precipitates tend to be cathodic sites. These findings are consistent with our results, where $\mathrm{VO}_{x}$ species, particularly $\mathrm{V}_{4} \mathrm{O}_{12}{ }^{4-}$ species, ${ }^{22}$ were shown to be deposited on $\mathrm{Al}-\mathrm{Cu}-\mathrm{Mn}-\mathrm{Fe}-\mathrm{Si}$ cathodic precipitates upon corrosion in $\mathrm{NaCl}$.

\subsection{LDH sealing at lower temperature}

As shown in previous sections, Li-Al-LDH structures can be grown in conditions similar to those for HWS (temperature of the bath of $95{ }^{\circ} \mathrm{C}$ ) and the new LDH sealing layers rendered higher anticorrosive performance than the current commercially used HWS. In an attempt to make the $\mathrm{Li}-\mathrm{Al}-\mathrm{LDH}-\mathrm{OH} / \mathrm{CO}_{3}$ sealing more competitive, less energy consuming "green" sealing process, further studies were carried out at lower temperature down to the room temperature.

No significant effect of the temperature is seen in the appearance (Fig. 10a, d, g and j) and morphology of the LDH layers (Fig. 10b-1). An important highlight is here drawn to the LDH sealing prepared at room temperature $\left(\mathrm{pH} 11 / 25^{\circ} \mathrm{C}\right)$. No visible layer covering the TSA was formed, but the pores are totally filled by LDH nanoflakes with morphology close to those obtained at higher bath temperatures. Moreover, the crystallinity of the LDH flakes was not significantly changed with temperature decrease. The XRD patterns of ESI Fig. S8. $\dagger$ show that the main LDH peaks of (002), (101) and (004) are slightly sharper at the highest temperature, proving that samples prepared under this condition have the highest crystallinity.

Several works have shown that is thermodynamically possible to have Li-Al-LDH layers formed and stabilized at room temperature, and they have a fast growth kinetics with low activation energies. ${ }^{15,16}$ Buchheit et al. has shown a Liconversion layers grown at $25{ }^{\circ} \mathrm{C}$ with similar morphology as 
those shown here. ${ }^{15}$ Recent findings reported by Visser et al. ${ }^{\mathbf{1 6}}$ have depicted $\mathrm{Li}-\mathrm{Al}-\mathrm{LDH}$ conversion layers being formed in defects of AA2024-T3 painted with Li salt containing formulation. The LDH structures were formed during a neutral salt spray test (ASTM B-117) close to room temperature $\left(35^{\circ} \mathrm{C}\right)$. Under these conditions, Li-based pigments dispersed in the coating were leached and reacted with the $\mathrm{Al}^{3+}$ of the aluminum surface to form LDH structures. ${ }^{\mathbf{1 6}}$

The corrosion protection properties of the samples treated at lower temperatures were studied by EIS (Fig. 11). These results demonstrate that the corrosion protection properties of the systems obtained at reasonably low temperatures are still quite acceptable. Even after one week of immersion test, the low frequency impedance remains at relatively high values for all the systems treated in full temperature range. For one system a well-defined time constant at about $1 \mathrm{~Hz}$ is clearly observed which is responsible for the inner barrier layer. The resistance of this layer after a week of immersion is still above $1 \mathrm{Mohm}$ $\mathrm{cm}^{2}$ confirming a remarkable corrosion protection especially considering the fact that the sealing treatment was performed at room temperature conditions. Overall, it is confirmed that the LDH sealing at higher temperatures increases the barrier properties of the TSA film, both porous and inner parts, but not significantly. Such a subtle improvement in the protective properties does not justify significant increase of costs associated with high temperature treatment. $\mathrm{Li}-\mathrm{Al}-\mathrm{LDH}-\mathrm{OH} / \mathrm{CO}_{3}$ grown on TSA-2024 at room temperature provides corrosion protection comparable to that offered by standard HWS procedure (Fig. 6b). The versatility of $\mathrm{Li}-\mathrm{Al}-\mathrm{LDH}$ and room

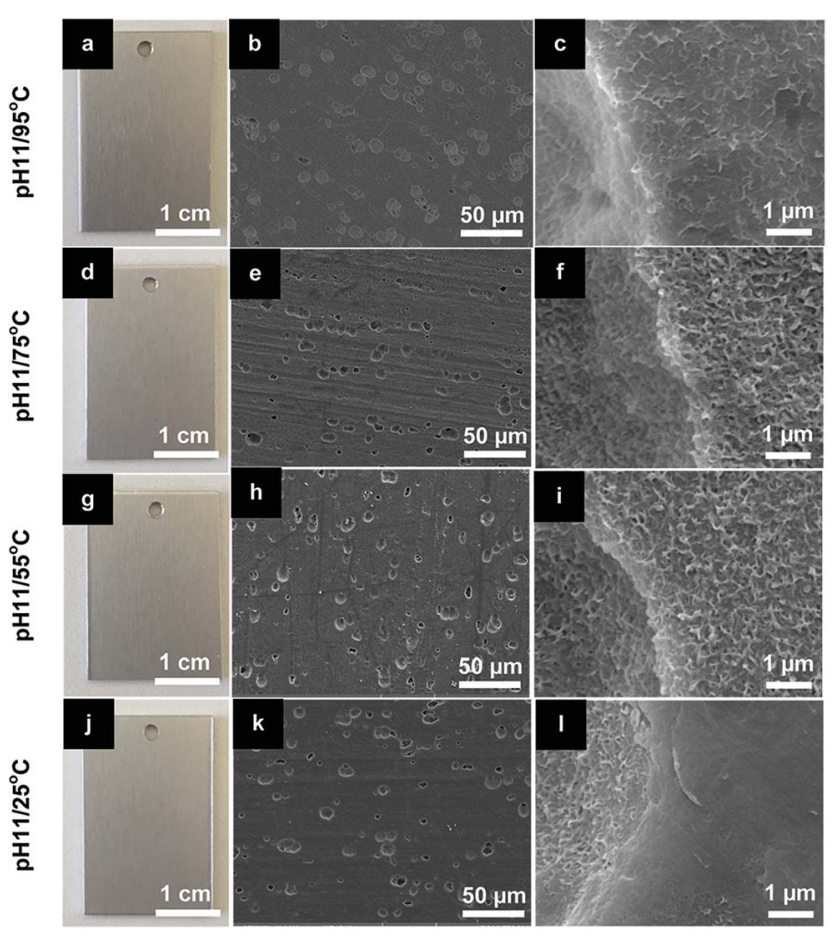

Fig. 10 Photographs and SEM images of $\mathrm{LDH}-\mathrm{OH} / \mathrm{CO}_{3}$ sealed TSA at $\mathrm{pH} 11$ for different bath temperatures: $(\mathrm{a}-\mathrm{c}) 95^{\circ} \mathrm{C}$; (d-f) $75^{\circ} \mathrm{C}$; $(\mathrm{g}-\mathrm{i})$ $55^{\circ} \mathrm{C}$; (j-l) $25^{\circ} \mathrm{C}$.
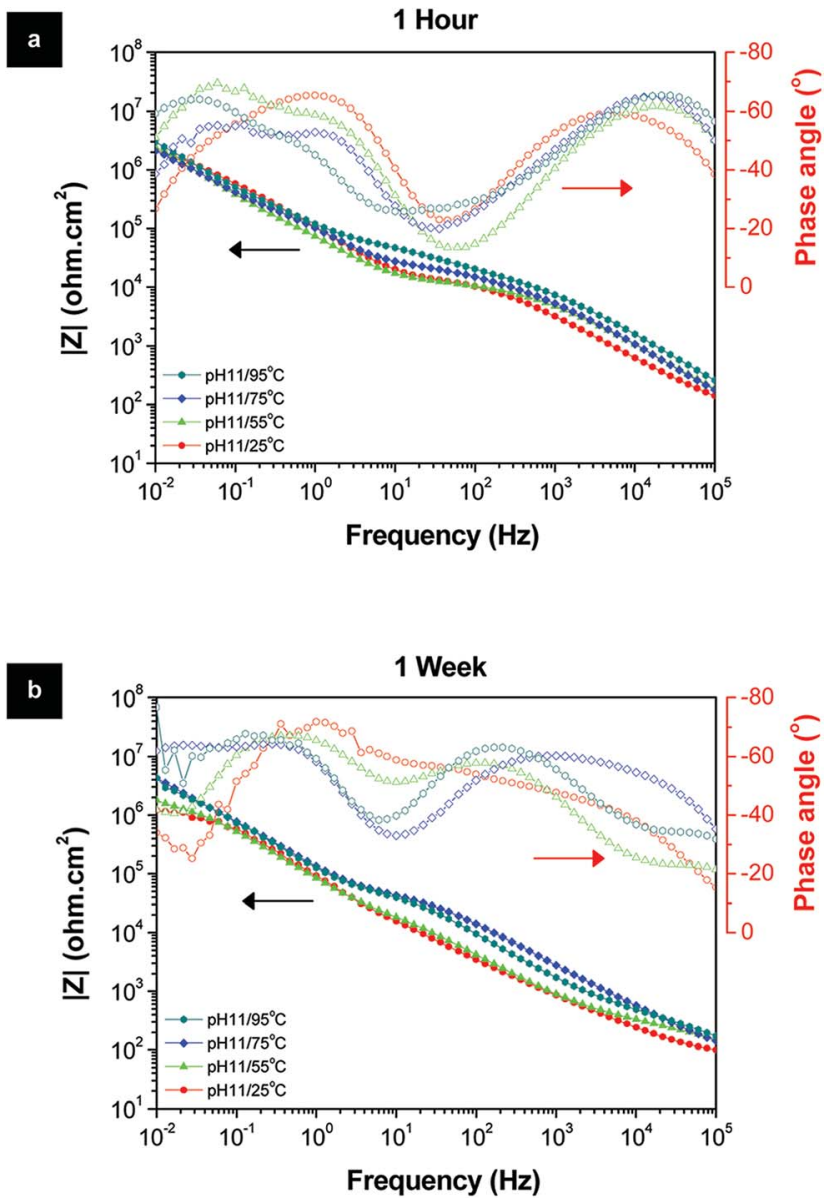

Fig. 11 Bode and phase angle plots of the $\mathrm{LDH}-\mathrm{OH} / \mathrm{CO}_{3}$ layers prepared at different temperatures after (a) 1 hour and (b) 1 week immersion in $0.05 \mathrm{M} \mathrm{NaCl}$ solution.

temperature preparation conditions sets its technological parameters window closer to industrial acceptance and exploitation with high cost operation savings expected.

\section{Conclusions}

The active protective sealing of TSA anodic layer was achieved via treatment of anodized AA2024-T3 in Li-containing baths. Li-Al$\mathrm{LDH}$ is formed in the porous layer as well as on the surface of the anodic film. LDH layers hosting vanadate corrosion inhibiting anions are used as "smart" reservoirs for the controlledrelease of the corrosion inhibitor via anion-exchange process.

The $\mathrm{Li}-\mathrm{Al}-\mathrm{LDH}-\mathrm{VO}_{x}$ active layers loaded with $\mathrm{VO}_{x}$ corrosion inhibiting species showed strong synergetic anti-corrosion performance, both barrier and active protection were identified, with overall performance better than the $\mathrm{Li}-\mathrm{Al}-\mathrm{LDH}-\mathrm{OH} /$ $\mathrm{CO}_{3}$ reference. EIS data for $\mathrm{LDH}-\mathrm{OH} / \mathrm{CO}_{3}$ and $\mathrm{LDH}-\mathrm{VO}_{x}$ sealed TSA show an increased barrier properties and improved stability of the dense oxide layer at the metal-porous oxide interface when compared to HWS treatment, while SVET shows an increased active inhibition of corrosion processes in artificial scribe defects. 
The Li-based sealing was also achieved at close to room temperature condition which is significantly lower than conventionally used temperatures for HWS. The low temperature treatments allow formation of LDH structures in the TSA layer and confer reasonably high corrosion resistance. The low temperature sealing has an important advantage over HWS or other sealing approaches, which require temperatures close to water boiling point.

\section{Acknowledgements}

This work has received funding from the European Union's Horizon 2020 research and innovation programme under grant agreement no. 645676 project MULTISURF. Dr M. Mohedano is grateful to MICINN (Spain) for financial support via Proyecto Retos Jovenes Investigadores MAT2015-73355-JIN. Dr S. V. Lamaka acknowledges the financial support of Alexander von Humboldt Foundation via Experienced Researcher Grant. Dr J. Tedim thanks FCT for the researcher grant IF/00347/2013. This work was developed in the scope of the project CICECO - Aveiro Institute of Materials, POCI-01-0145-FEDER-007679 (Ref. FCT UID/CTM/50011/2013), financed by national funds through the FCT/MEC and when applicable co-financed by FEDER under the PT2020 Partnership Agreement. Dr D. Mata would like to thank Dr Nico Scharnagl for the Raman scientific discussions. Authors acknowledge Mr Maksim Starykevich for carrying out the GDOES analyses.

\section{Notes and references}

1 E. Eichinger, Met. Finish., 1997, 95, 36-41.

2 M. Curioni, P. Skeldon, E. Koroleva, G. E. Thompson and J. Ferguson, J. Electrochem. Soc., 2009, 156, C147-C153.

3 M. García-Rubio, M. P. de Lara, P. Ocón, S. Diekhoff, M. Beneke, A. Lavía and I. García, Electrochim. Acta, 2009, 54, 4789-4800.

4 W. J. Wittke, Met. Finish., 1989, 87, 24-26.

5 G. A. Dorsey, J. Electrochem. Soc., 1966, 113, 169-172.

6 V. R. Capelossi, M. Poelman, I. Recloux, R. P. B. Hernandez, H. G. de Melo and M. G. Olivier, Electrochim. Acta, 2014, 124, 69-79.

7 G. Boisier, N. Pébère, C. Druez, M. Villatte and S. Suel, J. Electrochem. Soc., 2008, 155, C521-C529.

8 Y. Zuo, P.-H. Zhao and J.-M. Zhao, Surf. Coat. Technol., 2003, 166, 237-242.

9 R. L. Twite and G. P. Bierwagen, Prog. Org. Coat., 1998, 33, 91-100.

10 J. Tedim, M. L. Zheludkevich, A. N. Salak, A. Lisenkov and M. G. S. Ferreira, J. Mater. Chem., 2011, 21, 15464-15470.

$11 \mathrm{~K}$. A. Yasakau, J. Tedim, M. L. Zheludkevich and M. G. S. Ferreira, Corrosion, 2013, 70, 436-445.

12 J. Tedim, M. L. Zheludkevich, A. C. Bastos, A. N. Salak, A. D. Lisenkov and M. G. S. Ferreira, Electrochim. Acta, 2014, 117, 164-171.

13 B. Kuznetsov, M. Serdechnova, J. Tedim, M. Starykevich, S. Kallip, M. P. Oliveira, T. Hack, S. Nixon,
M. G. S. Ferreira and M. L. Zheludkevich, RSC Adv., 2016, 6, 13942-13952.

14 M. Serdechnova, M. Mohedano, B. Kuznetsov, C. L. Mendis, M. Starykevich, S. Karpushenkov, J. Tedim, M. G. S. Ferreira, C. Blawert and M. L. Zheludkevich, J. Electrochem. Soc., 2017, 164, C36-C45.

15 R. G. Buchheit, M. D. Bode and G. E. Stoner, Corrosion, 1994, 50, 205-214.

16 P. Visser, Y. Liu, H. Terryn and J. M. C. Mol, J. Coat. Technol. Res., 2016, 13, 557-566.

17 P. Visser, Y. Liu, X. Zhou, T. Hashimoto, G. E. Thompson, S. B. Lyon, L. G. J. van der Ven, A. J. M. C. Mol and H. A. Terryn, Faraday Discuss., 2015, 180, 511-526.

18 A. M. Fogg, J. S. Dunn and D. O'Hare, Chem. Mater., 1998, 10, 356-360.

19 P. K. Dutta and M. Puri, J. Phys. Chem., 1989, 93, 376-381.

20 L. Lei, F. Millange, R. I. Walton and D. O'Hare, J. Mater. Chem., 2000, 10, 1881-1886.

21 M. Iannuzzi and G. S. Frankel, Corros. Sci., 2007, 49, 23712391.

22 K. D. Ralston, S. Chrisanti, T. L. Young and R. G. Buchheit, J. Electrochem. Soc., 2008, 155, C350-C359.

23 J.-H. Syu, J.-Y. Uan, M.-C. Lin and Z.-Y. Lin, Corros. Sci., 2013, 68, 238-248.

24 Y. Zhang, J. Liu, Y. Li, M. Yu, S. Li and B. Xue, J. Coat. Technol. Res., 2015, 12, 595-601.

25 G. Boisier, A. Lamure, N. Pébère, N. Portail and M. Villatte, Surf. Coat. Technol., 2009, 203, 3420-3426.

26 M. García-Rubio, P. Ocón, A. Climent-Font, R. W. Smith, M. Curioni, G. E. Thompson, P. Skeldon, A. Lavía and I. García, Corros. Sci., 2009, 51, 2034-2042.

27 K. Okada, F. Matsushita and S. Hayashi, Clay Miner., 1997, 32, 299-305.

28 I. C. Chisem and W. Jones, J. Mater. Chem., 1994, 4, 17371744.

29 I. Sissoko, E. T. Iyagba, R. Sahai and P. Biloen, J. Solid State Chem., 1985, 60, 283-288.

30 M.-C. Lin, F.-T. Chang and J.-Y. Uan, J. Mater. Chem., 2010, 20, 6524-6530.

31 J. D. Phillips and L. J. Vandeperre, J. Nucl. Mater., 2011, 416, 225-229.

32 M. Serdechnova, A. N. Salak, F. S. Barbosa, D. E. L. Vieira, J. Tedim, M. L. Zheludkevich and M. G. S. Ferreira, J. Solid State Chem., 2016, 233, 158-165.

33 S. Britto, A. V. Radha, N. Ravishankar and P. V. Kamath, Solid State Sci., 2007, 9, 279-286.

34 V. Rives and M. A. Angeles Ulibarri, Coord. Chem. Rev., 1999, 181, 61-120.

35 J. W. Diggle, T. C. Downie and C. Goulding, Chem. Rev., 1969, 69, 365-405.

36 P. Campestrini, E. P. M. van Westing, H. W. van Rooijen and J. H. W. de Wit, Corros. Sci., 2000, 42, 1853-1861.

37 A. C. F. Ribeiro, A. J. M. Valente, V. M. M. Lobo, E. F. G. Azevedo, A. M. Amado, A. M. A. da Costa, M. L. S. Ramos and H. D. Burrows, J. Mol. Struct., 2004, 703, 93-101. 